\title{
An Exploratory Study on Personality Traits and Procrastination Among University Students
}

\author{
Chooi Seong Lai*, Abdul Rahman bin Ahmad Badayai, Khartikka Chandrasekaran, Siew Yen Lee, \\ Rubini Kulasingam
}

Faculty of Social Science, Arts and Humanities, Tunku Abdul Rahman University University, Kuala Lumpur, Malaysia

\section{Email address:}

laics@acd.tarc.edu.my (C. S. Lai), abdulrahman@acd.tarc.edu.my (A. R. Ahmad Badayai), khartikkac@acd.tarc.edu.my (K. Chandrasekaran), leesiewyen@acd.tarc.edu.my (S. Y. Lee), krubinik@acd.tarc.edu.my (R. Kulasingam)

\section{To cite this article:}

Chooi Seong Lai, Abdul Rahman bin Ahmad Badayai, Khartikka Chandrasekaran, Siew Yen Lee, Rubini Kulasingam. An Exploratory Study on Personality Traits and Procrastination Among University Students. American Journal of Applied Psychology. Special Issue: Psychology of University Students. Vol. 4, No. 3-1, 2015, pp. 21-26. doi: 10.11648/j.ajap.s.2015040301.14

\begin{abstract}
The present research examines the association between personality traits and procrastination behavior among 148 university students (52 males, 96 females). Respondents completed two measurements - Leonard Personality Inventory and General Procrastination Scale. Descriptive analysis indicated that Diploma Year 2 students scored the highest $($ Mean $=58.47)$, while Degree Year 1 students scored the lowest (Mean $=54.75)$ in the level of procrastination. Personality traits profiling consistently indicated that the most dominant personality trait of Diploma Year 2, Degree Year 1, 2 and 3 students is Neutral trait $($ Mean $=78.05,80.75,78.84 \&$ 76.82); while the least dominant trait is Decisiveness (Mean $=67.48,68.25,69.89 \& 68.33)$. The most dominant personality traits among male university students are Openness $($ Mean $=75.77)$, Decisiveness $($ Mean $=68.69)$ and Neutral (Mean $=78.48)$, while female university students are Analytical $($ Mean $=73.36)$ and Relational $($ Mean $=72.42)$. Meanwhile, male students scored slightly higher in procrastination (Mean $=58.25)$ as compared to females $($ Mean $=57.09)$. However, independent sample t-test indicated no significant gender differences in respondents' level of academic procrastination $[\mathrm{t}(146)=.702, \mathrm{p}>.05]$. Finally, correlational analyses reported no significant associations between the five personality traits with procrastination behavior among university students. Future studies should explore on whether cultural differences may influence personality traits and the level of academic procrastination of university students.
\end{abstract}

Keywords: Personality, Traits, Procrastination

\section{Introduction}

Students inculcate a variety of experiences in academic settings that influence their perceptions and behavior over their academic performances. One of the most important concerns in the field of educational psychology is to attempt to understand why some students stop striving when faced with academic difficulties, whereas others rise to the occasion using strategies and persistence, thus achieving higher grades. Nowadays, it is noticeable that many students easily give up on their life and accept failure leading to frustration thus affecting their self-regulation and decision-making. Therefore, students' preferred behavioural styles such as procrastination and personality traits such as emotional stability; extraversion or surgency, analytical and agreeableness can affect students' coping skills and ability to adapt to the ever challenging university life.

\section{Literature Review}

\subsection{Personality Traits and Procrastination}

Academic procrastination could be considered as a maladaptive behavior that can cause psychological distress on students. Soloman and Rothblum [1] defined procrastination to be an unnecessary act of postponing tasks and that students engaging in procrastination is an unfavorable habit in which they are more likely to complete a task only if it provides them with positive reinforcement and tasks with short term gains.

Results indicated by Yong [2] reported that males were more prone to delay work; whereby Sharma and Kaur's [3] study suggested that females were in higher risk of procrastinating due to fear of failure. However, according to Sirin [4], cultural factors were often looked into while discussing gender differences in procrastination. The studies 
of Ozer et al. [5] and Yong [6] reported that there were differences in the level of procrastination, whereby males procrastinated more than females. Ozer et al. [5] explained their findings through cultural differences, stating that Turkish women who are from a collectivism culture were expected by the society to be more successful and procrastinate lesser on their tasks. Research by Steel [6] also found that gender was significantly correlated with procrastination; while on the contrary, Islak [7] and another study conducted by Ozer and Ferrari [8] found no significant relationship between gender and procrastination.

However, such cultural differences may not be commonly found in the Malaysian context whereby males and females are expected to be equal in all aspects. Thus, there may not be any significant gender differences of academic procrastination among Malaysian university students.

Meanwhile, research by Wiley [9], Milgram and Tenne [10] and Hussain and Sultan [11] described academic procrastination as "to delay in making a decision on the performance of a task, a behavioural tendency towards procrastination or a personality characteristic". Poor personality traits such as emotional instability and poor analytical skill can also be linked to an indecisive situation in which a student might not be able to choose the right tools in managing their time and life which affects their quality of life which generally results in poor life satisfaction. Defeating habits such as procrastination due to certain personality traits can hinder students' and society's development.

Steel et. al. [12] stated that people who normally procrastinate may have a particular personality attributed to a predisposed emotion, or memory. In addition, she reported that academic procrastination can involve in delaying assignments or public speaking until the last minute which may lead to some psychological effects such as anxiety, stress, worry and low self-esteem.

Personality traits which have been reviewed in this study included openness to experience, conscientiousness, extraversion, agreeableness, and neuroticism. The most consistent findings from the previous studies showed that conscientiousness is a personality trait which can significantly predict procrastination as compared to the other personality domains $[13,14]$. These studies reported that individuals who demonstrated conscientiousness were found to be less likely to procrastinate. Conversely, those who demonstrated low levels of conscientiousness were reported to have higher tendency to procrastinate. In academic procrastination, this means that students who exhibit low emotional stability may delay in submitting assignments and delay in exam preparation as they may feel unable or unlikely to meet the expectation $[15,16]$. On the other hand, students with high emotional stability may have higher chances of academic success which may be protective against procrastination [12].

Extraversion is a personality trait which is quite similar to emotional stability, however it is more susceptible to an expressed, sociable, optimistic, outgoing, energetic and exciting orientation. It was found that students who exhibit higher levels of extraversion have lower coping skill for academic performance. Hence, it might lead them to have higher tendency in procrastination [16].

Lastly, most of the previous studies showed that openness to experience and agreeableness are not related to procrastination [14]. It is not clear why these two personality traits were not associated with procrastination and hence further studies are necessary. Vallerand [17] stated that agreeableness has been defined as a tendency to be more compassionate towards others. Individuals who score higher in these two personality domains are found to be more likely to get along with others but more importantly they would compromise their own interest with other people. Hence, these type of personality traits might be irrelevant to the process of procrastination as agreeableness reflects an interpersonal style rather than a behavioral trait [12].

\subsection{Research Objective}

In this study, the researchers are interested to explore the personality traits of university students, which are assessed by Leonard Personality Profiling (LPI). This study also intends to explore the behavioural dimension of procrastination which can hinder students' ability to manage their time and life effectively. The results of this study can help educators and students to blueprint a better and more conducive teaching and learning environment in the future.

Insufficient research taking into account of these variables in the Malaysian context has also prompted the researchers to explore this topic further. Since the Malaysian educational policies and parents emphasize on examinations and successful tertiary education, hence, local students may be pressured to adopt different regulatory and behavioural lifestyles in adapting to the challenging university learning environment. Results generated from Western countries might not completely be applicable in the Asian context. Cultural differences also contribute to different emphasis on different values affecting our Malaysian students' personality dimensions.

Hence, the general research objective of this study is to profile the personality traits of university students and to determine the procrastination levels between gender and respondents' year of study (diploma year 2, degree year 1, 2 \& 3). This study will further explore the associations between personality traits and procrastination among university students.

\subsection{Research Questions}

1. What are the different levels of procrastination between diploma and degree university students?

2. What are the different personality traits of diploma and degree students?

3. What are the gender differences in the profiles of personality traits among university students?

4. Are there significant gender differences in the level of procrastination among university students?

5. Are there significant relationships between personality traits and procrastination of university students? 


\section{Research Methodology}

\subsection{Respondents}

Using convenience sampling, 148 Psychology university students (both males and females) from the Faculty of Social Science, Arts and Humanities (comprising Diploma Year 2 and Bachelor degree Year 1, 2 \& 3), at a private University in Malaysia participated in this descriptive study on personality traits and academic procrastination.

\subsection{Instruments}

Two instruments were used to profile respondents' personality traits and assess the academic procrastination among university students. The details of the instruments used are described as follows:

Leonard Personality Inventory was developed by Leonard M. S. Yong [18] to specifically measure preferred personality styles of respondents on the dimensions of Openness, Analytical, Neutral, Relational and Decisiveness. Openness in LPI is similar to Openness trait in the Big Five Model [19], referring to individuals who are open to experience and are intellectually curious, open to emotion, and willing to try new things. They tend to be more creative and more aware of their feelings. Neutral is equivalent to Agreeableness trait which reflects preference for social harmony. These individuals are good in getting along with others, considerate, kind, generous, trusting and trustworthy, helpful, and willing to compromise their interests with others, and optimistic. Analytical trait of LPI is similar to Conscientiousness of the Big Five Model of Goldberg [19] which refers to traits of self-discipline, controlled, and regulated individuals. Relational is similar to Extraversion (or Surgency) referring to individuals who enjoy interacting with people, and are generally enthusiastic. Lastly, Decisiveness is equivalent to Emotional Stability which is contrary to Neuroticism of the Big Five Model. Decisive people tend to be highly goal oriented and sets out to accomplish results quickly, are risk-takers, and love challenges but may be impatient.

This instrument consists of 100 items ( structured into 20 items on each dimension) and each item rated on a 5-point Likert scale ranging from $1=$ Disagree strongly, $2=$ Disagree a little, $3=$ Neither agree or disagree, $4=$ Agree a little, $5=$ Agree strongly. The Cronbach Alpha internal homogeneity reliability coefficient obtained for each dimension on the Leonard Personality Inventory are as follows: Openness $=.79$; Neutral =.69; Analytical=.68; Relational=.76; Decisive $=.66$. Hence, the results showed a high inter-item correlation. Higher profiling score in a subscale means that the personality trait in that subscale is dominant.

General Procrastination Scale was developed by Lay [20] to measure the level of students' tendency to procrastinate on academic matters and tasks. The instrument comprised of 20 items and the scoring measurement is based on 5-point Likert scale ranging from $1=$ Extremely uncharacteristic, 2=Moderately Uncharacteristic, 3=Neutral, 4=Moderately Characteristic and 5=Extremely Characteristic. After reversely scoring items were coded, the scores for 20 items were summed up. Hence, the higher the score, the higher is the tendency for students to procrastinate on academic matters. The Cronbach Alpha reliability coefficient of the General Procrastination Scale was .82.

\section{Results}

The data collected were analysed using SPSS. Descriptive statistics was employed to explore the personality traits and procrastination level of respondents, while Pearson-Product-Moment correlation coefficient and independent sample t-test were used to assess the association and gender differences between the two variables.

Table 1. General Procrastination Scale (GPS)

\begin{tabular}{ll}
\hline Cronbach's Alpha & N of Items \\
\hline .788 & 20 \\
\hline
\end{tabular}

SPSS reliability analysis indicated that the 20 items of General Procrastination Scale (GPS) used in this study had obtained a Cronbach's Alpha value of .788. This implied that the instrument had high reliability and yielded a reliability value that was very similar to the pioneer of the instrument with Lay [20] obtaining a Cronbach's Alpha of .82.

Research Question 1: What are the different levels of procrastination between the diploma and degree university students?

Table 2. Procrastination of Respondents according to their year of study

\begin{tabular}{lll}
\hline & N & Procrastination (Mean value) \\
\hline Diploma Year 2 & 62 & 58.47 \\
Degree Year 1 & 8 & 54.75 \\
Degree Year 2 & 45 & 57.56 \\
Degree Year 3 & 33 & 56.27 \\
Total & 148 & \\
\hline
\end{tabular}

Table 2 indicated that Diploma Year 2 students are the most likely group to procrastinate academically (Mean $=58.47)$, followed by Degree Year $2($ Mean = 57.56) and Degree Year 3 students (Mean $=56.27)$. Among the degree students, the Year 2 students scored the lowest in their procrastination level which means that they are the most unlikely group to procrastinate as compared to their juniors (Year 1 students) and also seniors (Year 3 students).

Research Question 2: What are the different personality traits of the diploma and degree students?

Table 3. Personality Traits Profile of Respondents

\begin{tabular}{|c|c|c|c|c|c|c|}
\hline & $\mathbf{N}$ & 1 & 2 & 3 & 4 & 5 \\
\hline $\begin{array}{l}\text { Diploma Year } \\
2\end{array}$ & 62 & 72.37 & 72.65 & 67.48 & 78.05 & 71.58 \\
\hline Degree Year 1 & 8 & 70.13 & 75.00 & 68.25 & 80.75 & 77.25 \\
\hline Degree Year 2 & 45 & 72.38 & 74.44 & 68.25 & 80.75 & 72.91 \\
\hline Degree Year 3 & 33 & 74.97 & 71.88 & 68.33 & 76.82 & 70.33 \\
\hline
\end{tabular}

*Note: 1; Openness, 2: Analytical, 3: Decisiveness, 4: Neutral, 5: Relational

Personality traits profiling by LPI consistently indicated 
that the most dominant personality trait of the Diploma Year 2, Degree Year 1, 2 and 3 students is Neutral trait (Mean $=78.05$, $80.75,78.84 \& 76.82)$. The results also indicated that the least dominant trait of Diploma Year 2, Degree Year 1, 2 and 3 students is consistently Decisiveness trait (Mean $=67.48$, $68.25,69.89 \& 68.33)$.

For both Diploma Year 2 and Degree Year 2 students, they have the most dominant Neutral personality trait (Mean = $78.05 \& 78.84)$, followed by Analytical (Mean $=72.65 \&$ 74.44), Openness (Mean $=72.37 \& 72.38)$, Relational (Mean $=71.58 \& 72.91)$ and their least dominant trait is Decisiveness $($ Mean $=67.48 \& 71.88)$.

Whereas, for Degree Year 1 students, their most dominant trait is Neutral personality (Mean $=80.75$ ), followed by Relational $($ Mean $=77.25)$, Analytical $($ Mean $=75.00)$, Openness $($ Mean $=70.13$ ) and the least dominant is Decisiveness $($ Mean $=68.25)$.

Lastly, for the Degree Year 3 students, they have the most dominant Neutral trait (Mean $=76.82)$, followed by Openness $($ Mean $=74.97)$, Analytical $($ Mean $=71.88)$, Relational (Mean $=70.33$ ), and their least dominant trait is Decisiveness (Mean $=68.33$ ).

Research Question 3: What are the gender differences in the profiles of Personality traits among university students?

Table 4. Gender differences in personality profiles of respondents

\begin{tabular}{llll}
\hline & gender & N & Mean \\
\hline \multirow{2}{*}{ Openness } & female & 96 & 71.24 \\
& male & 52 & 75.77 \\
Analytical & female & 96 & 73.36 \\
& male & 52 & 72.75 \\
Decisiveness & female & 96 & 68.31 \\
\multirow{3}{*}{ Neutral } & male & 52 & 68.69 \\
& female & 96 & 77.99 \\
Relational & male & 52 & 78.48 \\
& female & 96 & 72.42 \\
& male & 52 & 71.27 \\
\hline
\end{tabular}

Descriptive statistics on gender comparison reported that the more dominant trait among male university students are Openness $($ Mean $=75.77)$, Decisiveness $($ Mean $=68.69)$ and Neutral traits (Mean $=78.48)$ as compared to female university students (Means $=71.24,68.69 \& 77.99$ ). However, the more dominant traits of female university students are Analytical $($ Mean $=73.36)$ and Relational traits $($ Mean $=72.42)$ as compared to male university students (Mean $=73.36 \&$ 71.27).

Research Question 4: Are there significant gender differences in the level of procrastination among university students?

Table 5. Gender Differences in Academic Procrastination of Respondents

\begin{tabular}{lllll}
\hline & & N & Mean & Std. Deviation \\
\hline Academic & Female & 96 & 57.09 & 9.538 \\
Procrastination & Male & 52 & 58.25 & 9.622 \\
& Total & 148 & & \\
& Gender & df & t-test & Sig. (2-tailed) \\
Academic & Female & 146.00 & .702 & .484 \\
Procrastination & Male & & & \\
\hline
\end{tabular}

The independent sample t-test analysis indicated that there was no significant differences between the female $(\mathrm{M}=57.09$, $\mathrm{SD}=9.538)$ and male $(\mathrm{M}=58.25, \mathrm{SD}=9.622)$ university students' level of academic procrastination $[\mathrm{t}(146)=.702$, $\mathrm{p}>$.05].

Research Question 5: Are there significant relationships between personality traits and procrastination of university students?

Table 6. Relationships between Personality Traits and Procrastination

\begin{tabular}{lll}
\hline & & Procrastination \\
\hline \multirow{5}{*}{ Openness } & Pearson Correlation & -.010 \\
& Sig. (2-tailed) & .900 \\
& $\mathrm{~N}$ & 148 \\
& Pearson Correlation & .068 \\
\multirow{5}{*}{ Decisive } & Sig. (2-tailed) & .414 \\
& $\mathrm{~N}$ & 148 \\
& Pearson Correlation & -.102 \\
& Sig. (2-tailed) & .216 \\
& $\mathrm{~N}$ & 148 \\
& Pearson Correlation & .025 \\
Relational & Sig. (2-tailed) & .761 \\
& $\mathrm{~N}$ & 148 \\
& Pearson Correlation & -.155 \\
& Sig. (2-tailed) & .061 \\
& $\mathrm{~N}$ & 148 \\
& Pearson Correlation & 1 \\
& Sig. (2-tailed) & 148 \\
\hline
\end{tabular}

**. Correlation is significant at the 0.01 level (2-tailed).

*. Correlation is significant at the 0.05 level (2-tailed).

Pearson Product Moment Correlation analysis reported that there were no significant associations between all the personality traits profiled by LPI (Openness, Analytical, Decisiveness, Neutral and Relational) with academic procrastination $(p>.05)$. There were very weak and negative association between Openness $(r=-.010)$, Decisiveness $(r=$ -.102) and Relational $(r=-.155)$ personality traits with academic procrastination; but were insignificant. Moreover, the statistical results also indicated very weak and positive relationship between Analytical $(\mathrm{r}=.068)$ and Neutral $(r=.025)$ traits with academic procrastination, but were insignificant.

In suffix, the results indicated that those university students who are open, decisive and relational are more likely to procrastinate; whereas those who are analytical and neutral will less likely to procrastinate. However, it is also noted that these correlational output are not significant.

\section{Discussion and Conclusion}

The present study seeks to clarify the different types of personality and procrastination by examining the personality constructs from a traits perspective. Overall, the results provided a great deal of insight into the nature of the personality-procrastination link. Majority of the students from the diploma and bachelor programs are of Neutral trait and the rest of them are of Decisiveness trait. It is difficult to conclude that the diploma students year 2 are more likely to 
procrastinate than bachelor students in year 2. This could be due to the insignificant association between all types of personality traits and the levels of procrastination.

The results obtained with this first sample indicated that there were no association between the types of personality and procrastination. The findings only indicated very weak and negative association for Openness, Decisiveness and Relational types. Although the results indicated that those university students who were open, decisive and relational were more likely to procrastinate, however the results emphasized otherwise. Many other factors might suggest possible explanations to the findings. Factors such as fear of failure, depression, anxiety, and the role of executive functions could have influenced the results of this research. Current research suggested that the association between personality and procrastination is more complex than what the past theorists had predicted $[21,22]$. Thus, this complexity stems from recent findings which indicated that the personality constructs are multidimensional and has personal, social and cultural components within.

Interestingly, the pattern of findings in this study indicated that the link between personality and procrastination is somewhat greater for males than for females; females were shown possessing more Analytical and Relational traits than male students. However, there are no significant differences between both genders. The present findings require further replication and any attempts to account for the differences between genders would be purely speculative at this juncture.

Several factors could have contributed to these differences between males and females, such as individual gender-related differences in reactions to loss of control, affiliated behaviors, cultural impact on how one defines procrastination as well as individual's motive [22]. Furthermore, Milgram et. al. [23] examined procrastination on everyday tasks and found that procrastination was associated with "covert negativism". According to Fleet et. al. [22] covert negativism was conceptualized as the extent to which a task is perceived as an imposition and the person resents being forced to do a task. Similarly, an individual perceives that other people are imposing unrealistic demands on the self.

The generalizability of these findings must be examined in samples that consist of a vast number of university/university students from various faculties. An important focus would be research on personality and procrastination among undergraduate and postgraduate students. Such research may provide important information about the developmental course of the personality-procrastination link as well as the causal sequence, stress-study related, anxiety if it does indeed exist. More researches are required in the future to explore on whether cultural differences may influence the level of academic procrastination in both males and females.

\section{References}

[1] Soloman, L.J., \& Rothblum, E.D. (1984). Academic procrastination: Frequency and cognitive-behavioral correlates. Journal of Counseling Psychology, 31(4).
[2] Yong, F.L. (2010). A study on the assertiveness and academic procrastination of English and Communication students at a private university. American Journal of Scientific Research, Issue 9, pp. 62-71.

[3] Sharma, M., \& Kaur, G. (2011). Gender differences in Procrastination and Academic Stress among adolescents. Indian Journal of Social Science Researches Vol. 8 No. 1-2, pp. 122-127.

[4] Sirin, E. F. (2011). Academic procrastination among undergraduates attending school of physical education and sports: Role of general procrastination, academic motivation and academic self-efficacy. Educational Research and Review, 6(5), 447-455.

[5] Ozer, B. U., Demir, A., \& Ferrari, J. R. (2009). Exploring academic procrastination among Turkish students: Possible gender differences in prevalence and reasons. Journal of Social Psychology, 149(2), 241-257.

[6] Steel, P. (2007). The nature of procrastination: A meta-analytic and theoretical review of quint es sential self-regulatory failure. Psychological Bulletin, 133(1), 65-94.

[7] Ruhsan Burcu Islak (2011). Academic procrastination in relation to gender among gifted and talented university students. Unpublished master's thesis, University of Houston, USA.

[8] Özer, B. U., \& Ferrari, J. R. (2011). Gender orientation and academic procrastination: Exploring Turkish high school students. Individual Differences Research, 9(1), 33-40.

[9] Wiley, J., \& Sons. (2000) Role conflict and academic procrastination: A self-determination perspective. European Journal of Social Psychology, 33(1), 135-145.

[10] Milgram, N., \& Tenne, R. (2000). Personality correlates of decisional and task avoidant procrastination. European Journal of Personality, 14 (1) 141-156.

[11] Hussain, I., \& Sultan, S. (2010). Analysis of procrastination among university students. Procedia Social and Behavioral Sciences, 5, 1897-1904.

[12] Steel, P., Brothen, T., \&Wambach, C. (2001. Procrastination and personality, performance, and mood. Personality and Individual Differences, 30, 95-106.

[13] Johnson, J.L., \& Bloom, A.M. (1995). An analysis of the contribution of the five factors of personality to variance in academic procrastination. Personality Individual Differences, 18(1), 127-133.

[14] Watson, D.C. (2001). Procrastination and the five-factor model: a facet level analysis. Personality and Individual Differences.30, 149-158.

[15] Rice, K.G., Richardson, C.M.E., \& Clark, D. (2012). Perfectionism, Procrastination, and Psychological Distress. Journal of Counseling Psychology, 59(2), 288-302.

[16] Gallagher, D. J. (1996) Personality, Coping, and Objective Outcomes: Extraversion, Neuroticism, Coping Styles, and Academic Performance. Personality Individual Differences, 21(3), 421-429

[17] Vallerand, R.J. (1995).Self-Regulation and Academic Procrastination. The Journal of Social Psychology, 135(5), 607-619. 
[18] Yong. M.S. (1999). Norms \& Technical Manual: The Leonard Personality Inventory (LPI). Leonard Personality Incorporated Sdn Bhd, Malaysia.

[19] Goldberg, L. R. (1992). The development of markers for the Big-Five factor structure. Psychological Assessment, 4(1), 26-42.

[20] Lay, C. H. (1986). At last, my research article on procrastination. Journal of Research in Personality, 20(4), 474-495.
[21] Fleet, G.L., Blankstein, K.K., Hewitt, P.L., Koledin, S.P. (1992). Components of perfectionism and personalities in university students. Social Behavior \& Personality, 20(2), 85-94.

[22] Fleet, G.L., Stainton, M., Hewitt, P.L., Sherry, S.B., \& Lay, C. (2012). Procrastination automatic thoughts as a personality construct: an analysis of the procrastinatory cognitions inventory. Springer Science.

[23] Milgram, N. A., Sroloff, B., \& Rosenbaum, M. (1988). The procrastination of everyday life. Journal of Research in Personality, 22, 197-212. 